\title{
ANALISIS PENGARUH JANGKA PENDEK DAN JANGKA PANJANG NILAI TUKAR DAN TINGKAT IMBALAN SBIS TERHADAP INFLASI DI INDONESIA PERIODE JANUARI 2009-DESEMBER 2015')
}

\author{
Tania Megasari \\ Mahasiswa Program Studi S1 Ekonomi Islam Fakultas Ekonomi dan Bisnis Universitas Airlangga \\ Email: Tania.megasari-12@feb.unair.ac.id
}

Tika Widiastuti

Departemen Ekonomi Syariah Fakultas Ekonomi dan Bisnis Universitas Airlangga

Email: tika.widiastuti@feb.unair.ac.id

\begin{abstract}
:
The purpose of this research is to examine the effect of the exchange rate, and the return rate of Bank Indonesia Sharia Certificate (SBIS) on inflation in Indonesia during the period January 2009 to December 2015. The approach used in this research is quantitative research using Error Correction Model (ECM) by Eviews program 8. The data used are secondary data from the official website of Bank Indonesia. The results showed that the Exchange rate and the rate of SBIS have a significant and positive correlation against inflation in the short term and long term during the period January 2009 to December 2015.
\end{abstract}

\section{Keywords : Inflation, SBIS, Exchange Rate}

\section{PENDAHULUAN}

Krisis ekonomi yang melanda Indonesia pada tahun 1998 mempunyai dampak negatif di antaranya adalah tingkat kepercayaan internasional yang menurun terhadap Indonesia, meningkatnya angka pemutusan kerja, menurunnnya daya beli masyarakat, kesenjangan yang mencolok diantara si kaya dan si miskin, melehanya nilai tukar vang rupiah terhadap dollar serta terjadi inflasi yang tinggi (Andarini:1)

Dalam memperbaiki fluktuasi nilai tukar dan tingginya tingkat harga, Bank Indonesia menerbitkan beberapa instrumen moneter baik untuk perbankan konvensional dan syariah. Salah satunya adalah Sertifikat Bank Indonesia Syariah (SBIS). SBIS merupakan surat berharga berdasarkan prinsip syariah berjangka waktu pendek dalam mata vang rupiah yang diterbitkan oleh Bank Indonesia

dengan menggunakan akad ju'alah (Kawiryawan, 2015:2).

Bank Indonesia dapat mempengaruhi dan mengarahkan berbagai aktivitas ekonomi dan keuangan untuk mencapai tujuan akhir yang diinginkan atau dicapai melalui instrumen kebijakan moneter (Humaniora, 2010:1). Kebijakan moneter menurut Warjiyo dan Solikin (2003:2) merupakan kebijakan otoritas moneter yang dilakukan oleh bank sentral dalam bentuk pengendalian moneter dengan upaya mengendalikan besaran moneter dalam pencapaian kondisi perekonomian yang diinginkan suatu negara. Mekanisme transmisi kebijakan moneter di Indonesia yang dilakukan Bank Indonesia sebagai otoritas moneter dapat mempengaruhi berbagai kegiatan ekonomi dan perdagangan. Seperti yang tertera pada UndangUndang No. 3 tahun 2004 pada pasal 7 1) Jurnal ini merupakan bagian dari skripsi dari Tania Megasari, NIM 041211432096 yang diuji pada 30 Januari 2017 
Megasari, et al/Jurnal Ekonomi Syariah Teori dan Terapan Vol. 4 No. 11 November 2017: 928-936; ANALISIS PENGARUH JANGKA PENDEK DAN JANGKA PANJANG NILAI TUKAR DAN TINGKAT IMBALAN SBIS TERHADAP INFLASI DI INDONESIA PERIODE JANUARI 2009-DESEMBER 2015

yang menyatakan bahwa Indonesia telah menganut kebijakan moneter dengan tujuan tunggal, yaitu untuk mencapai dan memelihara kestabilan nilai sistem rupiah. Agar tercapai tujuan tersebut, Bank Indonesia mempunyai beberapa tugas diantaranya adalah menetapkan dan melaksanakan kebijakan moneter (Warjiyo dan Agung, 2002:3-4)

$$
\text { Inflasi tinggi merupakan }
$$

permasalahan utama pada perekonomian karena pada masa inflasi seluruh harga dan upah tidak bergerak pada tingkat yang sama, maka muncul harga relatif. Penyimpangan harga relatif menghasilkan dua akibat inflasi yaitu, redistribusi pendapatan dan kekayaan di antara kelompok yang berbeda dan terjadinya penyimpangan pada harga relatif dan output barang yang berbeda (Samuelson dan Nordhaus, 2001:387). Melihat pentingnya penjagaan stabilitas harga atau tingkat inflasi yang rendah, maka koordinasi kebijakan tingkat inflasi diharapkan dapat mengendalikan tingkat inflasi pada tingkat yang rendah, dan stabil hal ini dapat diupayakan agar tingkat inflasi tidak menganggu aktivitas perekonomian secara umum, dan menghambat pertumbuhan ekonomi.

Berangkat dari latar belakang yang telah dijabarkan di atas penulis mengangkat judul skripsi ini dengan: "Analisis Pengaruh Jangka Pendek Dan Jangka Panjang Nilai Tukar Dan Tingkat Imbalan SBIS Terhadap Inflasi Di Indonesia Periode Januari 2009-Desember 2015." Penulis mengambil judul ini dengan tujuan untuk mengetahui apakah tingkat imbalan sertifikat Bank Indonesia syariah (SBIS) dan nilai tukar berpengaruh terhadap inflasi baik jangka pendek maupun jangka panjang. Penulis berharap dengan adanya penelitian ini akan muncul informasi baru dan sebagai alat pembelajaran yang bermanfaat bagi para pembacanya.

\section{LANDASAN TEORI}

Menurut Warjiyo dan Solikin (2003:2) kebijakan moneter merupakan kebijakan bank sentral dalam bentuk pengendalian besaran moneter untuk mencapai perkembangan kegiatan perekonomian yang diinginkan. Kebijakan moneter adalah semua upaya atau tindakan Bank Sentral dalam mempengaruhi perkembangan variabel moneter (uang beredar, suku bunga kredit dan nilai tukar) untuk mencapai tujuan ekonomi tertentu (Mishkin, 2008:457).

Manurung (2001: 126) menyatakan bahwa valuta asing (foreign exchange) adalah mata vang negara lain (foreign currency) dari suatu perekonomian. Nilai tukar valuta asing ditentukan dalam pasar valuta asing, yaitu pasar tempat mata uang yang berbeda. Pasar valuta asing pada dasarnya adalah jaringan kerja (network) dari perbankan dan dan lembaga keuangan yang melaluinya mata-mata uang dapat ditukarkan (Manurung, 2001:127). Menurut 
Megasari, et al/Jurnal Ekonomi Syariah Teori dan Terapan Vol. 4 No. 11 November 2017: 928-936; ANALISIS PENGARUH JANGKA PENDEK DAN JANGKA PANJANG NILAI TUKAR DAN TINGKAT IMBALAN SBIS TERHADAP INFLASI DI INDONESIA PERIODE JANUARI 2009-DESEMBER 2015

Samuelson (2001:305), nilai tukar mata vang merupakan harga satuan mata vang dalam mata vang lain. Nilai tukar vang mempresentasikan tingkat harga pertukaran dari satu mata vang ke matang vang lainnya dan digunakan dalam berbagai transaksi internasional.

Kebijakan moneter menurut Karim (2011: 177-180) adalah keberadaan vang dalam sebuah perekonomian memberikan arti yang terpenting, ketidakadilan dari alat tukar yang diakibatkan adanya instabilitas nilai tukar yang mengakibatkan perekonomian pada titik keseimbangan. Huda (2008:54) menjelaskan bahwa suatu negeri tidak akan mungkin melakukan pembangunan secara berkesinambungan tanpa adanya keadilan dalam sistem yang dianutnya.

Nilai tukar dapat dirumuskan sebagai harga mata uang suatu negara yang diekspresikan dalam ukuran beberapa mata uang lainnya (Levi, 2001:103). Menurut Paul Krugman dan Obstfeld (2003:388) perubahan nilai tukar dapat dibedakan menjadi dua, yaitu depresiasi dan apresiasi. Nilai tukar mata uang suatu negara mengalami depresiasi ketika nilai mata uangnya relatif menurun terhadap nilai mata vang negara lain. Sebaliknya, nilai tukar mata uang suatu negara mengalami apresiasi ketika nilai mata uangnya relatif meningkat terhadap nilai mata vang negara lainnya.

Peraturan Bank Indonesia No.10/11/PBI/2008 tentang Sertifikat Bank Indonesia Syariah mendefinisikan SBIS sebagai surat berharga berdasarkan prinsip syariah berjangka pendek dalam mata uang rupiah yang diterbitkan oleh Bank Indonesia. Fatwa Dewan Syariah Nasional No. 64/DSN-MUI/XII/2007 menjelaskan bahwa SBIS merupakan instrumen pengganti moneter syariah dengan prinsip ju'alah yang sebelumnya bernama Sertifikat Wadi'ah Bank Indonesia (SWBI) dengan prinsip wadi'ah.

Sertifikat Bank Indonesia Syariah (SBIS) merupakan surat berharga berdasarkan prinsip syariah yang memiliki jangka waktu pendek dalam mata vang rupiah yang diterbitkan oleh Bank Indonesia.

Dilihat dari hukum islam, SBIS merupakan bagian kegiatan muamalah dimana pelaksanannya pada segala aspek harus memenuhi segala nilai-nilai islam yang didasarkan pada sumber hukum yang utama yaitu Al-Qur'an dan Hadits (Hapsari, 2013:19). Salah satu Firman Allah tentang prinsip bermuamalah terdapat dalam Q.S. An-Nisa Ayat 29: 
Megasari, et al/Jurnal Ekonomi Syariah Teori dan Terapan Vol. 4 No. 11 November 2017: 928-936; ANALISIS PENGARUH JANGKA PENDEK DAN JANGKA PANJANG NILAI TUKAR DAN TINGKAT IMBALAN SBIS TERHADAP INFLASI DI INDONESIA PERIODE JANUARI 2009-DESEMBER 2015

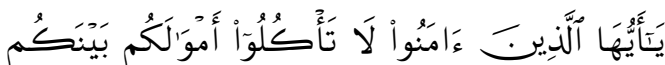

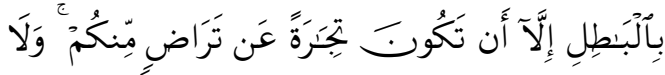

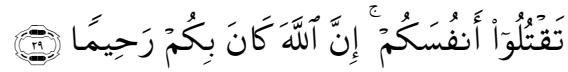

Artinya : Hai orang-orang yang beriman, janganlah kamu saling memakan harta sesamamu dengan jalan yang batil, kecuali dengan jalan perniagaan yang Berlaku dengan suka sama-suka di antara kamu. dan janganlah kamu membunuh dirimu.

Ayat diatas menunjukkan bahwa Islam memperbolehkan umat muslim untuk bermuamalah selama kegiatan tersebut dilandasi atas dasar sukarela dan bukan dilakukan dengan cara yang batil, yaitu pelanggaran terhadap ketentuan agama atau persyaratan yang disepakati (Shihab, 2009:499).

Inflasi merupakan proses terjadinya kenaikan harga-harga umum secara terus menerus. Kenaikan harga dari satu atau dua barang saja tidak disebut inflasi, kecuali jika kenaikan harga barang tersebut meluas atau dapat mengakibatkan kenaikan harga sebagian besar dari barangbarang lain. Terdapat dua jenis inflasi, yaitu inflasi yang muncul karena adanya kenaikan permintaan yang disebut dengan demand-pull inflation, dan inflasi yang muncul akibat adanya penurunan penawaran agregat yang disebut dengan costpush inflation (Boediono, 2005:162).
Pada kerangka kebijakan moneter yang telah ditetapkan oleh Bank Indonesia, inflasi merupakan target akhir dari kebijakan moneter itu sendiri.

Menurut Mankiw (2006:195), inflasi merupakan fenomena moneter berupa peningkatan harga yang tearjadi tidak hanya pada satu barang melainkan harga barang secara umum dan secara terus menerus. Menurut Samuelson dan Nordhaus (2001:118), inflasi merupakan kenaikan di dalam tingkat harga umum. Dapat kita simpulkan dari definisi-definisi tersebut bahwa jika hanya satu atau beberapa harga barang saja pada saat tertentu dan tidak dalam jangka waktu yang lama belum tentu menimbulkan inflasi.

\section{Hubungan Nilai Tukar Terhadap Inflasi}

Teori yang biasa digunakan untuk menjelaskan hubungan antara nilai tukar dengan inflasi adalah Purchasing Power Parity (PPP). PPP merupakan paritas daya beli, tingkat inflasi dinilai paling mewakili terhadap nilai uang secara riil karena menggambarkan daya beli atau nilai tukar dengan barang atau jasa.

\section{Hubungan SBIS Terhadap Inflasi di Indonesia}

SBIS merupakan instrumen moneter islam yang dipergunakan oleh Bank Indonesia untuk mengendalikan inflasi. Apabila terjadi kenaikan inflasi Bank Indonesia akan berusaha untuk menarik dana di masyarakat lebih besar melalui lelang SBIS. Agar dana 
Megasari, et al/Jurnal Ekonomi Syariah Teori dan Terapan Vol. 4 No. 11 November 2017: 928-936; ANALISIS PENGARUH JANGKA PENDEK DAN JANGKA PANJANG NILAI TUKAR DAN TINGKAT IMBALAN SBIS TERHADAP INFLASI DI INDONESIA PERIODE JANUARI 2009-DESEMBER 2015

masyarakat yang beredar dapat lebih banyak di tarik oleh Bank Indonesia maka Bank Indonesia menaikan tingkat imbalan SBIS sebaliknya, apabila laju inflasi menurun untuk meningkatkan jumlah vang yang beredar bank Indonesia akan menurunkan tingkat imbalan SBIS sehingga masyarakat tidak tertarik untuk membeli SBIS.

\section{METODE PENELITIAN}

\section{Pendekatan Penelitian}

Dalam penelitian ini, pendekatan yang di gunakan adalah kuantitatif eksplanasi. Dalam penelitian ini akan membuktikan pengaruh nilai tukar dan tingkat imbalan SBIS terhadap inflasi di Indonesia sesuai dengan hipotesis yang saya tetapkan.

\section{Definisi Operasional}

1. Nilai Tukar $\left(X_{1}\right)$

Nilai tukar merupakan nilai dari unit mata vang domestik yang dibandingkan dengan mata vang negara lainnya. Nilai tukar dinyatakan dalam satuan rupiah. Data nilai tukar merupakan data nilai kurs tengah rupiah terhadap Dollar AS.

2. Tingkat Imbalan SBIS (X2)

Tingkat Imbalan Sertifikat Bank Indonesia Syariah merupakan tingkat imbalan yang mengacu pada tingkat diskonto hasil lelang SBI berjangka waktu sama. Tingkat imbalan SBIS dinyatakan dalam satuan persentasi.

3. Inflasi $(Y)$

Inflasi merupakan kenaikan hargaharga secara umum dan secara terus menerus. Inflasi dinyatakan dalam satuan persentasi.

\section{Jenis dan Sumber Data}

Jenis data yang digunakan berupa data runtut waktu (time series) tahun 2009-2015 dengan unit data bulanan. Data yang digunakan adalah data sekunder yang berasal dari Statistik Ekonomi dan Kevangan Indonesia (SEKI). Sumber-sumber lainnya yaitu diperoleh dari buku-buku, literature, dan internet.

\section{Prosedur Pengumpulan Data}

Prosedur pengumpulan data yang dilakukan oleh peneliti adalah mengumpulkan data penelitian yang bersumber dari data sekunder (BI), serta studi kepustakaan yang dilakukan dengan mengumpulkan dan mempelajari berbagai buku pustaka, jurnal ilmiah, artikel, dan sumber-sumber lain yang dapat digunakan untuk memahami permasalahan dan mendapatkan alternatif pemecahan masalah yang ada.

\section{Teknik Analisis}

Teknik Analisis yang digunakan dalam penelitian ini adalah analisis Error Correction Model (ECM). Model ECM pertama kali diperkenalkan oleh Sargan yang kemudian dipopulerkan oleh EagleGranger. Model ECM mempunyai kegunaan untuk mengatasi masalah data time series yang tidak stasioner pada 
Megasari, et al/Jurnal Ekonomi Syariah Teori dan Terapan Vol. 4 No. 11 November 2017: 928-936; ANALISIS PENGARUH JANGKA PENDEK DAN JANGKA PANJANG NILAI TUKAR DAN TINGKAT IMBALAN SBIS TERHADAP INFLASI DI INDONESIA PERIODE JANUARI 2009-DESEMBER 2015

tingkat level yang dapat menyebabkan terjadinya masalah regresi lancung. Salah satu keuntungan penggunaan ECM adalah bisa mengetahui hubungan jangka pendek dan jangka panjang antara variabel independen dengan variabel dependen.

\section{Uji Stasioneritas Data}

Stasioneritas data dapat dilihat dengan menggunakan uji akar unit (unit root test). Uji akar unit diperkenalkan oleh David Dickey dan Wayne Fuller. Uji ini bertujuan untuk mengetahui apakah data time series mengandung akar unit atau tidak. Jika suatu data mengandung akar unit maka data tersebut tidak dapat dianalisis setiap waktu. Jika data tersebut diregres maka akan menyebabkan timbulnya regresi lancung yang berarti bahwa data tersebut tidak dapat diestimasi atau palsu.

\section{Hasil dan Pembahasan}

\section{Hasil ECM}

1. Uji Stasioner Data

Tabel 1

\begin{tabular}{|c|c|c|c|c|}
\hline \multirow{2}{*}{$\begin{array}{c}\text { Varia } \\
\text { bel }\end{array}$} & \multirow{2}{*}{$\begin{array}{c}\text { ADF t- } \\
\text { statistik }\end{array}$} & \multicolumn{3}{|c|}{ MacKinnon Critical } \\
& & $1 \%$ & $5 \%$ & $10 \%$ \\
\cline { 3 - 5 } & & - & - & - \\
& & & \\
& & 4.073 & 3.465 & 3.1593 \\
& & 859 & 548 & 2 \\
\hline KURS & -2.106380 & - & - & - \\
& & 4.072 & 3.464 & 3.1589 \\
& & 415 & 865 & 74 \\
\hline rSBIS & -2.085105 & - & - & - \\
& & 4.075 & 3.466 & 3.1597 \\
& & 340 & 248 & 80 \\
\hline
\end{tabular}

Tabel 1 menunjukkan bahwa seluruh variabel yang di uji tidak stasioner pada derajat $1 \%$. Hasil dari pengujian pertama pada tingkat level menunjukkan bahwa seluruh variabel tidak stasioner, maka selanjutnya dilakukan pengujian pada first difference - trend and intercept. Tabel 2

\begin{tabular}{|c|c|c|c|c|}
\hline $\begin{array}{c}\text { Variab } \\
\text { el }\end{array}$ & $\begin{array}{c}\text { ADF t- } \\
\text { statisti } \\
k\end{array}$ & \multicolumn{3}{|c|}{$\begin{array}{c}\text { MacKinnon Critical } \\
\text { Value }\end{array}$} \\
\cline { 3 - 5 } $\mathrm{D}(\mathrm{INF})$ & - & - & $5 \%$ & $10 \%$ \\
& 5.6175 & 4.0753 & 3.4662 & - \\
& 60 & 40 & 48 & -1597 \\
& - & - & - & - \\
\hline $\mathrm{D}$ (KUR & - & - & - \\
$\mathrm{S})$ & 7.8807 & 4.0738 & 3.4655 & 3.1593 \\
& 96 & 59 & 48 & 72 \\
\hline & & & & \\
\hline $\mathrm{D}$ (rSBIS & - & - & - & - \\
l & 4.6807 & 4.0753 & 3.4662 & 3.1597 \\
& 61 & 40 & 48 & 80 \\
\hline
\end{tabular}

Pada tabel 2 tersebut dapat dilihat bahwa pada bentuk First Difference-trend and intercept semua variabel stasioner di tingkat first difference-trend and intercept baik di tingkat kesalahan $1 \%, 5 \%$, maupun $10 \%$.

2. Uji Kointegrasi

Uji kointegrasi dilakukan untuk mengetahui apakah akan terjadi keseimbangan dalam jangka panjang, yaitu terdapat kesamaan pergerakan dan stabilitas hubungan diantara variabel-variabel di dalam penelitian ini atau tidak.

Tabel 3

\begin{tabular}{|c|c|c|}
\hline Variabel & $\begin{array}{c}\text { ADF-Stat } \\
\text { (level) }\end{array}$ & Prob. \\
\hline$U(-1)$ & -6.164526 & 0.0000 \\
\hline
\end{tabular}


Megasari, et al/Jurnal Ekonomi Syariah Teori dan Terapan Vol. 4 No. 11 November 2017: 928-936; ANALISIS PENGARUH JANGKA PENDEK DAN JANGKA PANJANG NILAI TUKAR DAN TINGKAT IMBALAN SBIS TERHADAP INFLASI DI INDONESIA PERIODE JANUARI 2009-DESEMBER 2015

\begin{abstract}
Hasil analisis tersebut menunjukkan bahwa residual stasioner pada tingkat first difference dan terkointegrasi. Hal ini menunjukkan bahwa terdapat keseimbangan jangka panjang antara variabel independen dengan variabel dependen.
\end{abstract}

3. Estimasi ECM

ECM merupakan model dinamis yang mendapat perhatian besar para ekonom beberapa tahun terakhir ini. ECM menghasilkan koefisien koreksi kesalahan yang menunjukkan adanya fenomena dikoreksinya penyimpangan menuju ekuilibrium. Hal itu dapat diketahui dari adanya kointegrasi pada variabel yang diamati melalui Error Correction Term (ECT) yang signifikan.

Tabel 4

Hasil Estimasi ECM Jangka Pendek

\begin{tabular}{|c|c|c|}
\hline \multicolumn{3}{|c|}{ Variabel Dependen : D (INF) } \\
\hline Variabel & Koefisien & Prob. \\
\hline$D$ (KURS) & 0.000638 & 0.0543 \\
\hline$D$ (RSBIS) & 0.531589 & 0.0409 \\
\hline C & -0.065377 & 0.4157 \\
\hline ECT & -0.105773 & 0.0765 \\
\hline R-squared & 0.109911 \\
\hline
\end{tabular}

Berdasarkan tabel 4 yang menunjukkan hasil jangka pendek maka persamaan dapat disusun sebagai berikut:

$D\left(I N F_{t}\right)=-0.065377-0.105773 E C T+$ 0.000638 (KURSt) +0.531589 (rSBISt)

Persamaan diatas dapat menjelaskan pengaruh dari variabel nilai tukar dan tingkat imbalan SBIS terhadap variabel inflasi. Berikut ini akan dijelaskan pengaruh masing-masing variabel dalam jangka pendek:

1. Variabel Nilai Tukar Variabel nilai tukar dalam jangka pendek mempunyai koefisien sebesar 0.000638. Artinya, setiap peningkatan nilai tukar sebesar 1 maka nilai tukar akan meningkat sebesar 0.000638 .

2. Variabel Tingkat Imbalan SBIS

Variabel tingkat imbalan SBIS mempunyai koefisien sebesar 0.531589. Artinya, setiap peningkatan tingkat imbalan SBIS sebesar 1 maka tingkat imbalan SBIS akan meningkat sebesar 0.531589 .

3. Variabel ECT

Nilai koefisien dari ECT sebesar 0.0765 dan secara statistik signifikan $(0.0765<0,1)$, ini berarti model ECM dalam penelitian ini dapat dipakai untuk menganalisis model. Selain mengenai interprestasi ECT, nilai ECT sebesar 0.0765 menunjukkan bahwa kecepatan penyesuaian (speed of adjustment) produktivitas menuju ke kondisi keseimbangan adalah 0.0765 per tahun.

$$
\text { Koefisien determinasi }\left(R^{2}\right)
$$
sebesar $10,91 \%$ menunjukkan bahwa dalam jangka pendek perubahan variabel dependen dapat dijelaskan oleh perubahan 
Megasari, et al/Jurnal Ekonomi Syariah Teori dan Terapan Vol. 4 No. 11 November 2017: 928-936; ANALISIS PENGARUH JANGKA PENDEK DAN JANGKA PANJANG NILAI TUKAR DAN TINGKAT IMBALAN SBIS TERHADAP INFLASI DI INDONESIA PERIODE JANUARI 2009-DESEMBER 2015

variabel independen di dalam model sebesar 10,91\%, sisanya dijelaskan oleh variabel lain yang tidak dimasukkan di dalam model. Hasil estimasi ECM jangka panjang dapat dilihat pada tabel 5 sebagai berikut:

Tabel 5

\begin{tabular}{|c|c|c|}
\hline \multicolumn{3}{|c|}{ Dependen Variabel: INF } \\
\hline Variabel & Koefisien & Prob \\
\hline KURS & 0.000324 & 0.0047 \\
\hline rSBIS & 0.501751 & 0.0021 \\
\hline C & -0.940774 & 0.4230 \\
\hline \multicolumn{2}{|c|}{ R-squared } & 0.289493 \\
\hline
\end{tabular}

Berdasarkan tabel 4.4, yang menunjukkan hasil estimasi ECM jangka panjang maka dapat disimpulkan persamaan sebagai berikut:

$$
\begin{aligned}
& \operatorname{lnf} f_{\dagger}=-0.940774+ \\
& 0.000324 K U R S+0.501751 r S B I S_{+}
\end{aligned}
$$
menjelaskan pengaruh dari variabel nilai tukar dan tingkat imbalan SBIS terhadap variabel inflasi. Berikut ini akan dijelaskan pengaruh dari masing-masing variabel dalam jangka panjang:

1. Variabel Nilai Tukar Variabel nilai tukar dalam jangka panjang mempunyai koefisien sebesar 0.000324. Artinya, setiap peningkatan nilai tukar sebesar 1 maka inflasi akan meningkat sebesar 0.000324 .

2. Variabel tingkat imbalan SBIS Variabel tingkat imbalan SBIS dalam jangka panjang mempunyai koefisien sebesar 0.501751. Artinya, setiap peningkatan tingkat imbalan SBIS sebesar 1 maka inflasi akan meningkat sebesar 0.501751 .

Koefisien determinasi

sebesar 28,94\% menunjukkan bahwa dalam jangka panjang perubahan variabel dependen dapat dijelaskan oleh perubahan variabel independen di dalam model sebesar 28,94\%, sisanya dijelaskan oleh variabel lain yang tidak dimasukkan di dalam model.

\begin{tabular}{|c|c|c|c|c|}
\hline $\begin{array}{l}\text { Esti } \\
\text { masi }\end{array}$ & $\begin{array}{c}\text { Varia } \\
\text { bel } \\
\text { depe } \\
\text { nden }\end{array}$ & $\begin{array}{l}\text { Variab } \\
\text { el } \\
\text { indep } \\
\text { enden }\end{array}$ & $\begin{array}{c}\text { Pro } \\
\text { b }\end{array}$ & Ket \\
\hline \multirow{2}{*}{$\begin{array}{l}\text { Jan } \\
\text { gka } \\
\text { Panj } \\
\text { ang }\end{array}$} & \multirow[t]{2}{*}{ INF } & KURS & $\begin{array}{l}0.0 \\
047\end{array}$ & $\begin{array}{l}\text { Signif } \\
\text { ikan }\end{array}$ \\
\hline & & rSBIS & $\begin{array}{l}0.0 \\
021\end{array}$ & $\begin{array}{l}\text { Signif } \\
\text { ikan }\end{array}$ \\
\hline \multirow{2}{*}{$\begin{array}{l}\text { Jan } \\
\text { gka } \\
\text { Pen } \\
\text { dek }\end{array}$} & \multirow[t]{2}{*}{$\mathrm{D}$ (INF) } & $\begin{array}{c}\mathrm{D}(\mathrm{KUR} \\
\mathrm{S})\end{array}$ & $\begin{array}{l}0.0 \\
543\end{array}$ & $\begin{array}{c}\text { Signif } \\
\text { ikan }\end{array}$ \\
\hline & & $\begin{array}{l}D(r S B I S \\
\text { ) }\end{array}$ & $\begin{array}{l}0.0 \\
409\end{array}$ & $\begin{array}{l}\text { Signif } \\
\text { ikan }\end{array}$ \\
\hline
\end{tabular}

4. Uji $\dagger$

Tabel 5

tabel 5 menunjukkan hasil estimasi jangka panjang dan jangka pendek. Hasil estimasi uji † jangka panjang menunjukkan variabel nilai tukar dan tingkat imbalan SBIS berpengaruh signifikan terhadap inflasi. Hasil estimasi uji $\dagger$ jangka pendek menunjukkan variabel nilai tukar dan tingkat imbalan SBIS berpengaruh signifikan terhadap inflasi. 
Megasari, et al/Jurnal Ekonomi Syariah Teori dan Terapan Vol. 4 No. 11 November 2017: 928-936; ANALISIS PENGARUH JANGKA PENDEK DAN JANGKA PANJANG NILAI TUKAR DAN TINGKAT IMBALAN SBIS TERHADAP INFLASI DI INDONESIA PERIODE JANUARI 2009-DESEMBER 2015

Pembahasan

\section{Pengaruh Nilai Tukar terhadap Inflasi}

Hasil estimasi menunjukkan bahwa nilai tukar dalam jangka pendek memiliki koefisien sebesar 0.000638 dengan probabilitas 0.0543 dan koefisien jangka panjang sebesar 0.000324 dengan probabilitas 0.0047 yang signifikan pada a $10 \%$. Dapat disimpulkan dalam jangka pendek mupun jangka panjang nilai tukar mempengaruhi inflasi secara positif.

\section{Pengaruh SBIS terhadap Inflasi}

Hasil estimasi menunjukkan bahwa tingkat imbalan SBIS dalam jangka pendek memiliki koefisien sebesar 0.531589 dengan probabilitas 0.0409 dan dalam jangka panjang memiliki koefisien sebesar 0.501751 dan probabilitas 0.0047 yang signifikan pada a $10 \%$. Dapat disimpulkan bahwa dalam jangka pendek maupun panjang, tingkat imbalan SBIS mempengaruhi inflasi secara positif.

\section{SIMPULAN}

Berdasarkan pada analisis dan pembahasan yang dijelaskan dalam bab 4, maka didapatkan kesimpulan bahwa keseluruhan variabel independen berpengaruh terhadap variabel dependen baik dalam jangka pendek maupun jangka panjang dengan arah pengaruh positif
Berdasarkan kesimpulan diatas, saran yang disampaikan dalam penelitian ini adalah :

1. Dalam hal ini Bank Indonesia sebagai regulator moneter, diharapkan untuk memperhatikan pengendalian inflasi agar tidak salah dalam pengambilan keputusan serta menentukan kebijakan yang sesuai dengan kondisi perekonomian saat ini.

2. Bagi pemerintah sebagai pemegang kekuasaan atas kebijakan-kebijakan yang berlaku di Indonesia agar mempertimbangkan dengan matang setiap kebijakan yang diputuskan.

3. Penelitian yang akan datang disarankan untuk menambah variabel, subyek penelitian dan periode penelitian untuk mendapatkan hasil penelitian yang lebih baik.

\section{DAFTAR PUSTAKA}

Andarini, Marisa Ayu.2016. Pengaruh Transmisi Moneter Syariah: Sertifikat Bank Indonesia Syariah dan Pasar Uang Antar Bank Syariah terhadap Operasi Moneter Syariah dalam Mempengaruhi Inflasi di Indonesia Pada Periode 2011-2015. Skripsi tidak diterbitkan. Surabaya Fakultas Ekonomi Dan Bisnis Universitas Airlangga.

Boediono. 2005. Ekonomi Moneter. Edisi Pertama. Yogyakarta: PT BPFE. 
Megasari, et al/Jurnal Ekonomi Syariah Teori dan Terapan Vol. 4 No. 11 November 2017: 928-936; ANALISIS PENGARUH JANGKA PENDEK DAN JANGKA PANJANG NILAI TUKAR DAN TINGKAT IMBALAN SBIS TERHADAP INFLASI DI INDONESIA PERIODE JANUARI 2009-DESEMBER 2015

Hapsari, Nadhifa Alim. 2013. Pengaruh Tingkat Imbalan Sertifikat Bank Indnonesia Syariah (SBIS) terhadap Tingkat Pembiayaan dan Profitabilitas Bank Umum Syariah di Indonesia. Skripsi tidak diterbitkan. Surabaya Fakultas Ekonomi Dan Bisnis Universitas Airlangga.

Huda, Nurul, dkk. 2008. Ekonomi Makro Islam: Pendekatan Teoritis. Jakarta: Kencana Prenada Media Grup.

Humaniora, Traversa. 2010. Analisis Pengaruh Shock Bunga SBI, SukU Bunga Kredit Investasi dan Suku Bunga Deposito Berjangka pada Bank Umum terhadap Laju Inflasi di Indonesia. Skripsi tidak diterbitkan. Surabaya: Fakultas Ekonomi dan Bisnis Universitas Airlangga.

Karim, Adiwarman A. 2011 . Ekonomi Makro Islami. Edisi Kedua. Jakarta: PT. RajaGrafindo Persada.

Kawiryawan, Naroh. 2009. Pengaruh Tingkat Imbalan Sertifikat Bank Indonesia Syariah (SBIS) terhadap Penempatan Dana pada SBIS dan Profitabilitas Bank Umum Syariah di Indonesia. Skripsi tidak diterbitkan. Surabaya Fakultas Ekonomi Dan Bisnis Universitas Airlangga.

Krugman, Paul R. Dan Maurice Obstfeld. 2003. International Economics:

Theory and Policy. Sixth Edition. USA:

Addison Wesley Publishing Company.

Levi, Maurice D. 2001. Keuangan

Internasional. Terjemahan.

Yogyakarta: Andi.
Mankiw, N. Gregory. 2006. Teori Ekonomi Makro. Edisi Keempat. Terjemahan. Jakarta: Penerbit Erlangga.

Manurung, Mandala dan Prahatma Rahardja. 2001. Uang, Perbankan, dan Ekonomi Moneter (Kajian Kontekstual Indonesia). Jakarta: FEUI. Mishkin, Frederic S. 2008. Ekonomi Uang, Perbankan, dan Pasar Keuangan. Edisi Ke-8. Buku 1. Terjemahan oleh Lina Soelistianingsih dan Beta Yulianita G. Jakarta: Salemba Empat.

Rifanto, Akhmad. 2009. Tinjauan Hukum Islam Terhadap Akad Jualah dalam Ketentuan Mekanisme Penerbitan Sertifikat Bank Indonesia Syariah. Skripsi tidak diterbitkan. Surabaya Fakultas Syariah Insitut Agama Islam Negeri Sunan Ampel.

Samuelson, Paul A and William D. Nordhaus. 2001. Macroeconomics. 17th Edition. New York: McGraw-Hill Higher Education.

Shihab, Quraish. 2009. Tafsir Al Mishbah Volume 5. Jakarta: Lentera Hati

Warjiyo, Perry dan Solikin. 2003. Kebijakan Moneter di Indonesia. Jakarta: Pusat Pendidikan dan Studi Kebanksentralan Bank Indonesia.

Warjiyo, Perry dan Juda Agung. 2002. Transmission Mechanisms of Monetary Policy in Indonesia. Directorate of Economic Research and Monetary Policy. Jakarta: Bank Indonesia. 